\title{
3D Finite Element Modeling and Simulation of Friction Drilling Process
}

\author{
Nimmagadda Srilatha, Balla Srinivasa Prasad, Padmaja Anipey
}

\begin{abstract}
Friction drilling is an advanced drilling process in which that can be utilize the heat produced between the workpiece and rotating drilling tool bit to soften the work material and producing a hole on it. In this investigation our interest is to choose work material is Al 7075-T351 to analyze the stress, strain, temperature and work material deformation in friction drilling. Al 7075-T351 square-tube materials were drilled on a computer numerical control (CNC) machine centre by friction drilling has analyzed at different rotational speed and feed rate through controlled operation tests. The temperatures in work piece and tool were more in Friction drilling. Simulation has required perceiving the material flow, stresses, temperatures, and strains. Those are tough to quantify experimentally through friction drilling. In this study, CATIA is used to design the tool model and the software which is used to simulate the performance of friction drilling is DEFORM-3D and effect of tool material speed and feed rate on shape of bushing formed is observed. Taguchi's technique L9 Orthogonal Array was used to analyze the optimum values. Signal to noise ratios also administered for optimization of parameters.
\end{abstract}

Keywords: Friction drilling, DEFORM 3D, cutting temperature.

\section{INTRODUCTION}

Now a days friction drilling become getting more recognition technique in hole making with bushing generation process. For research and industrial application it was more engrossment technique. A special tool require for this process for forcing through work piece that will heated up and form a bushing. But here Friction drilling is the new technique going to experiment in aluminium, steel and Titanium alloys with the use of tungsten carbide tool. Friction drilling also called friction stair drilling, thermal drilling, and flow drilling is an unconventional machining process [1]. In Friction drilling no chip was formed that was the most advantage in this process, so that no pollution reduced machining time, minimal tool wear and longer tool life [2]. Generally bush shape depending

Revised Manuscript Received on December 30, 2019.

* Correspondence Author

Nimmagadda Srilatha*, Department of Mechanical Engg, VNRVJIET, Hyderabad, India. Email: srilatha7477@gmail.com

Balla Srinivasa Prasad, Department of Mechanical Engg,, GIT, GITAM Deemed to be University, Visakhapatnam, India. Email: bsp.prasad@gmail.com

Padmaja Anipey, Asst.professor, Dept. of Mechanical Engg, Vizag Institute of Technology, Visakhapatnam, India. Email: padmaja.anipey@gmail.com

(C) The Authors. Published by Blue Eyes Intelligence Engineering and Sciences Publication (BEIESP). This is an open access article under the CC BY-NC-ND license (http://creativecommons.org/licenses/by-nc-nd/4.0/) upon proportion of work material thickness $(\mathrm{t})$, and Drill bit diameter (d) .Height of bushing was approximately 2-3 times of material thickness[3]. Ozler et al. [4] and some other performed an experimental investigation of hole geometry in friction Drilling of AISI 1010 Steel when the feed decreasing and speed increases temperature at hole zone increase. Similarly, good geometry of washer was gets at more speed, and at the same time bushing height expanded. Demir [5] investigate the both diameter and depth of traditionally pre-drilling effect on the frictional heat, bushing shape, and the initial deformation in Friction drilling of A7075-T651 aluminium alloy, some are found the cylindrical shape with minimum petal formation and cracks at time of pre-drilling depths bigger than its length and pre-drilling diameter close to the end diameter of the tip of the tool. Raju and Swamy [6] performed that FEM analysis of friction drilling using DEFORED-3D they predicted that when feed, speed increase stress decreases. Miller et al. [7] performed Friction drilling of cast metals to machining of aluminum Al380 as well as AISI 1020 carbon steel used and explored experimentally the relationship between axial thrust force and torque under different spindle speeds and feed rates. Miller et al. [8] performed on Experimental and Numerical Analysis of the Friction Drilling Process Under the constant tool feed rate, the experimentally measured thrust force and torque were analyzed. Figure 1 shows systematic representation of Friction drilling it has different stages Tool composed of five regions center region which will be the angle alpha $(\alpha)$ and height (hc). This region is generally initiates more force and heat. Conical region has the angle $\beta$ (beta) and height. This has sharper than the center region, the shoulder region which region rubs against the work material and helps in bush forming. The cylindrical region has diameter $\mathrm{d}$ and height $\mathrm{hl}$. This helps to shape the bushing. The shank region is to form the boss on the hole and this will help to grip the tool at tool holder of the machine [9].

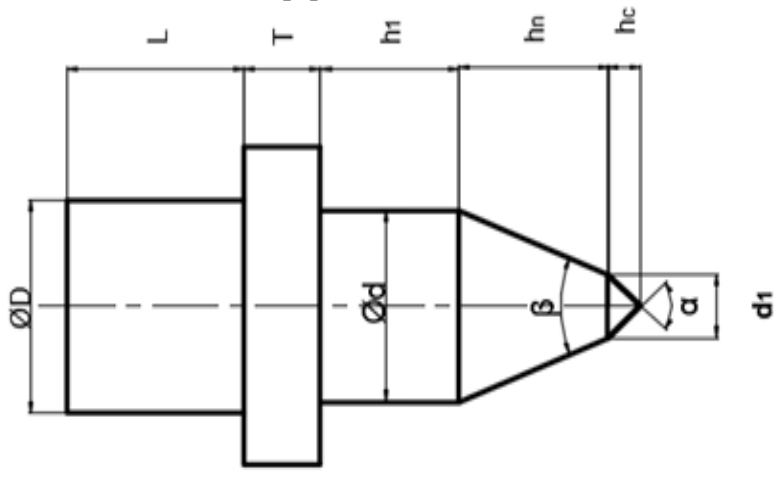

Figure 1 Geometry friction drilling tool

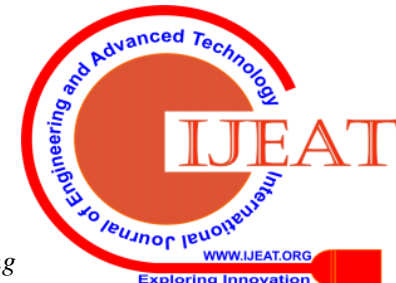




\section{D Finite Element Modeling and Simulation of Friction Drilling Process}

\section{EQUIPMENT SETUP, METHODOLOGY AND MATERIALS}

In this Friction drilling A CNC milling machine was employed.A7075-T351aluminum alloy sheets with $3 \mathrm{~mm}$ in thickness were used as work material.

The experimental setup was shown in following Figure 2. The tool was machined by Tungsten material with conical angle of $36^{\circ}$ and diameter of $8 \mathrm{~mm}$ where different speeds 3000, 3500 and 4000rpm, and feed rates are 30, 40, and 50 $\mathrm{mm} / \mathrm{min}$.

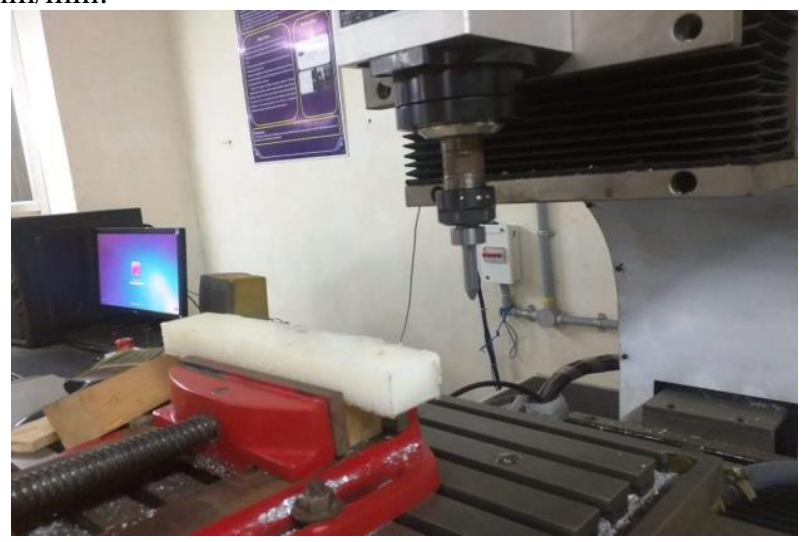

Figure 2Experimental setup (high speed 3 axis vertical CNC machine)

The aim of the study is modeling and simulation of friction drilling with tungsten Tool. Aluminum work piece is drilled. Friction drilling process is analyzed and simulated in DEFORM-3D software [10-11]. The variation of effective stain, effective stress and formation of bushing are in Friction drilling were analyzed. Finite component simulations were administered for various feeds keeping speed constant in DEFORM-3D. From simulations, varying elements like stresses, strains, velocities temperature distribution are often observed. Mechanical properties of tool and workpiece as follows in Table 1.

Table 1 Mechanical properties of tool and workpiece

\begin{tabular}{|l|l|l|l|}
\hline S.no & $\begin{array}{l}\text { Mechanical } \\
\text { properties }\end{array}$ & $\begin{array}{l}\text { Tungsten } \\
\text { carbide } \\
\text { (WC) }\end{array}$ & AL7075-T351 \\
\hline 1 & $\begin{array}{l}\text { Young's } \\
\text { modulus(GPa) }\end{array}$ & 600 & 72 \\
\hline 2 & Poisons ratio & 0.2 & 0.3 \\
\hline 3 & $\begin{array}{l}\text { Thermal } \\
\text { conductivity(W/m.k) }\end{array}$ & 88 & 130 \\
\hline 4 & $\begin{array}{l}\text { Thermal } \\
\text { expansion }\left(10^{6} / \mathrm{K}\right)\end{array}$ & 7.1 & 23.2 \\
\hline 5 & Density $\left(\mathrm{Mg} / \mathrm{m}^{3}\right)$ & 15.88 & 2.8 \\
\hline 6 & $\begin{array}{l}\text { Specific } \\
\text { heat(J/Kg-k) }\end{array}$ & 184 & 960 \\
\hline
\end{tabular}

The formation of the depth of hole and bushing are two necessary points to calculating the in Friction drilling. The observations of the bushing formation, roundness, depth, petal formation, and roughness, were created to gauge the favorable of Friction drilling hole. The shape of bushing of AL7075-T351 at various speeds is being studied. A major effect in bush form is observed by varying the spindle speed and feed rates. The temperature was decreased at high spindle speed; the bushing form remains poor at the extreme spindle speed. Notable petal formation was observed at each of the hole [12].

\section{RESULTS AND DISCUSSIONS}

\subsection{Simulation of friction drilling using DEFORM-3D}

Friction drilling method is simulated and analyzed with the help of DEFORM-3D software. The variation of effective strain, effective stress, and bushing formation of thermal drilling were observed. FEM simulation has administered to various feeds and speed in DEFORM-3D. As per simulation analysis, variables such as total forces, strains, stresses, temperature distribution and velocities are often obtained. However, all these are very tough to measure experimentally.
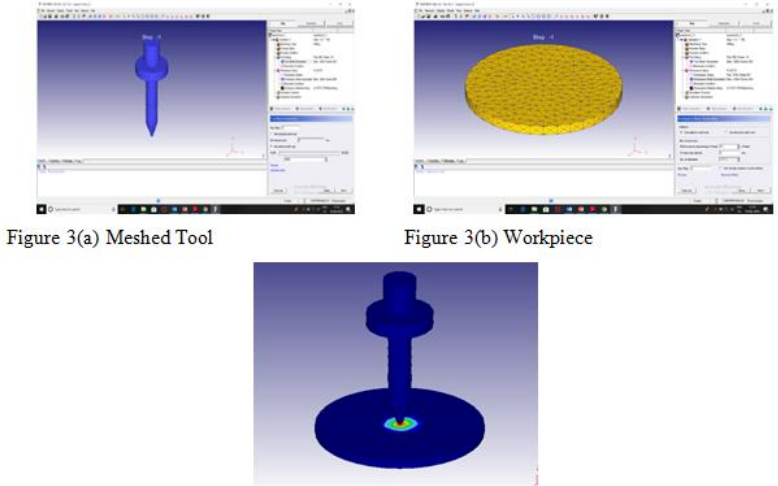

Figure 3(c) Initial stage of Friction drilling.

Figure 3(a) gave the meshed model tungsten carbide tool and meshed model of the work piece Al 7075-T351 presented in Figure 3(b). Hear deformed 3D software use for modeling and simulating the busing shape and hole formation in Friction drilling. Figure 3(c) gave the initial position of friction drilling when the tool tip will contact with the work piece, at this stage temperature of tool will transfer to wok material and it start melting.

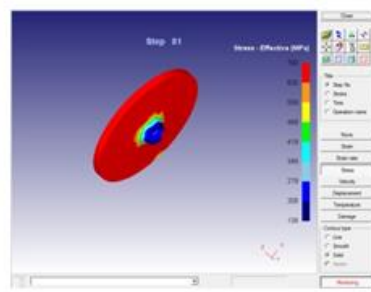

Figure 4.(a)
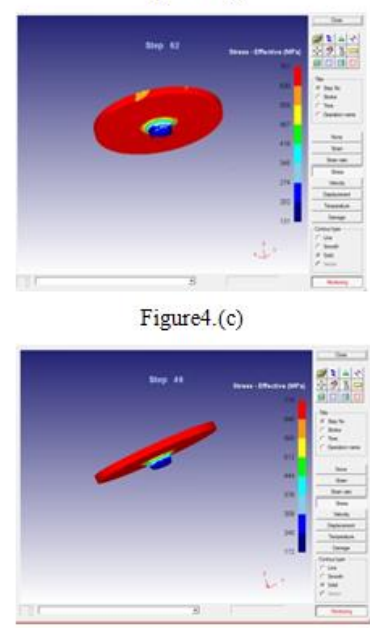

Figure 4.(e)

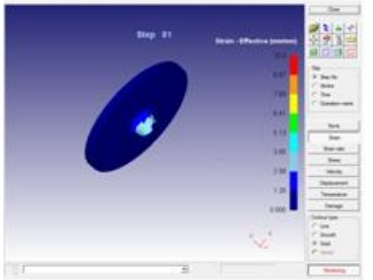

Figure 4.(b)

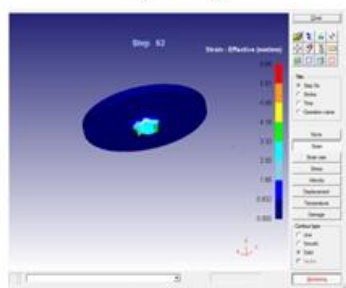

Figure4.(d)

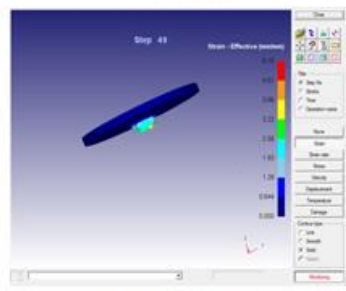

Figure 4.(f)
Figure 4 Bush formation at $3000 \mathrm{rpm}$ and 30, 40 and $50 \mathrm{~mm} / \mathrm{min}$ at feed rate 
The views of bushing forming at bottom surface of the work piece are shown to compare variation in bushing and hole at different speed with different feed rate.

As discussed in the introduction, present research work is aimed at the speed and feed rates will effect on effective stress and effective strain. Thus, to validate results at various speed and different feed rates. Figure 4 represents the 3D finite element simulation results at different feed rates with constant speed. The main purpose of this stage is to show the effect of speed and feed rate on bushing formation and hole geometry. Figures 4(a) to 4 (f) shows that bushing form, effective stress and effective strain at constant speed of 3000rpm and feed 30, 40, and $50 \mathrm{~mm} / \mathrm{min}$. while observing Figures 4(a) to 4 (f) when feed increases effective stress increase and effective strain decreases . Similarly feed decreases temperature increases. We will get better bushing at speed of 3000rpm and feed rate of $50 \mathrm{~mm} / \mathrm{min}$.

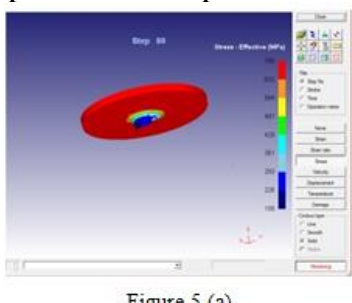

Figure 5.(a)

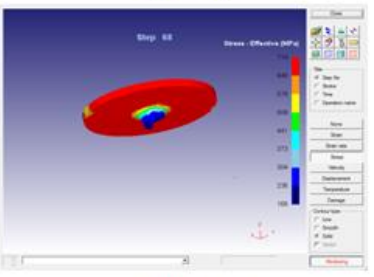

Figure 5.(c)

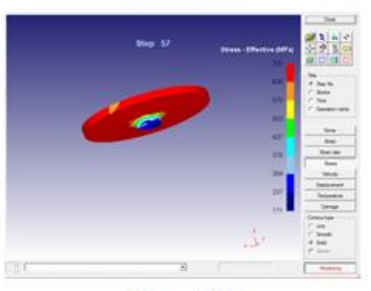

Figure 5.(e)

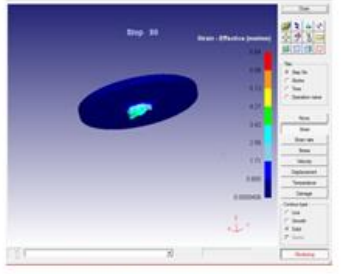

Figure 5.(b)

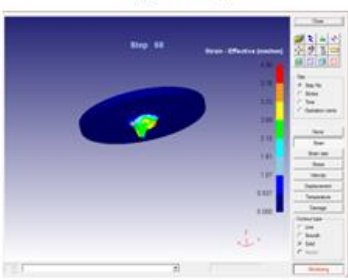

Figure 5.(d)

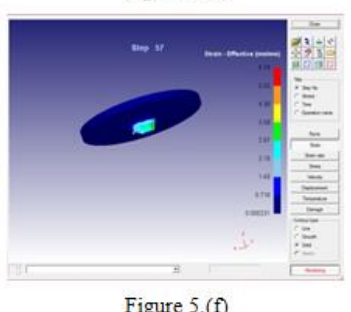

Figure 5.(f)
Figure 5 Bush formation at 3500 rpm with 30, 40 and $50 \mathrm{~mm} / \mathrm{min}$ feed rates

Figure 5 represents the 3D finite element simulation results at different feed rates with constant speed. The main purpose of this stage is to show the effect of speed and feed rate on bushing formation and hole geometry. Figure 5(a) to 5 (f) shows that bushing form, effective stress and effective strain at constant speed of 3000rpm and feed 30, 40, and 50 $\mathrm{mm} / \mathrm{min}$. when feed decreases temperature increases.

Similarly when feed decreases effective strain increases. Better hole geometry occur at 4000rpm at feed of 50 $\mathrm{mm} / \mathrm{min}$. Similarly, Figure 6 represents the 3D finite element simulation results at different feed rates with constant rotational speed of $4000 \mathrm{rpm}$. The main purpose of this stage is to show the effect of speed and feed rate on bushing formation and hole geometry. Figure 6(a) to 6(f) presents the formation of bush, corresponding effective stress and effective strain at constant speed of 4000rpm and feed 30, 40, and $50 \mathrm{~mm} / \mathrm{min}$. when feed decreases temperature increases. Similarly when feed decreases effective strain increases. Better hole geometry occur at 4000rpm at feed of 50 $\mathrm{mm} / \mathrm{min}$.
While observing above figures 4 to 6 when the speed increase temperature may also increase because of temperature is dependent on mechanical and thermal properties of the material. In generally while doing any machining when the cutting speed increases simultaneously the temperature also increases at the interface between tool and work piece. This will cause in softening of the work material. As the time of temperature increases which will result in Expansion or contraction of a structure at the stage stress will be increased [13].

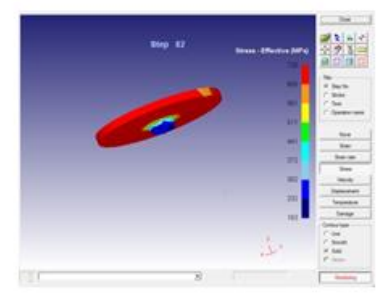

Figure 6.(a)

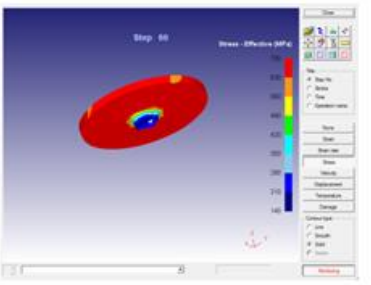

Figure 6.(c)

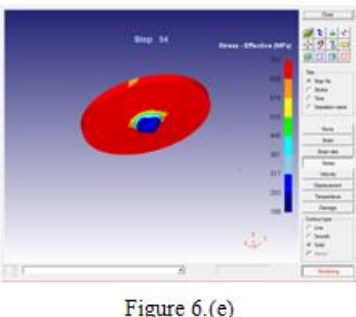

Figure 6.(e)

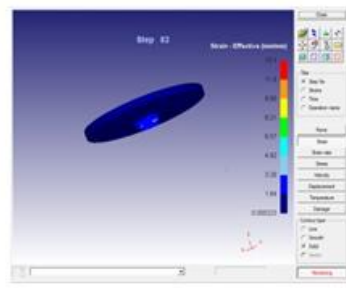

Figure 6.(b)

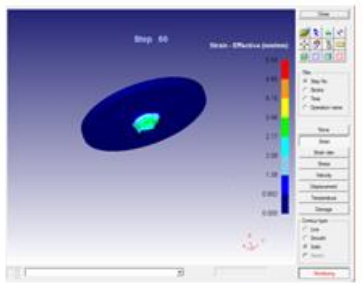

Figure 6.(d)

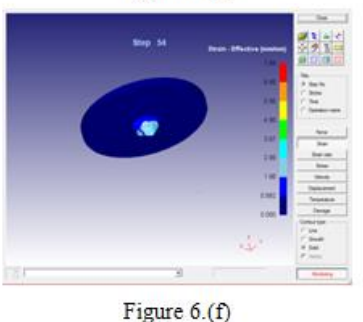

Figure 6 Bush formation at $4000 \mathrm{rpm}$ with 30, 40 and $50 \mathrm{~mm} / \mathrm{min}$ feed rates

\subsection{Taguchi analysis}

With the help Taguchi analysis design of experiments were conducted and analyzed the obtained result. In this Taguchi analysis we can able to obtain various graphs like $\mathrm{S} / \mathrm{N}$ ratio, means, and correlation between any two parameters [BSME]. Taguchi analysis uses for optimization process in 2-steps. Step-1 identifies the control factors that will be reduced variability with the use of Signal- to - noise ratio. Step-2 control factors identifies that move the mean to target and have a small or no effect on the signal-to-noise ratio.

\subsubsection{Signal to noise ratio analysis}

It is a very useful parameter and also a most significant by considering variation and target with samples of two sets, by comparing mean alone. It uses ANNOVA calculations in Taguchi method of DOE. In general it will be quality characteristics are

1. "Nominal is Better"

2. "Bigger is better"

3. "Smaller is better" 


\section{D Finite Element Modeling and Simulation of Friction Drilling Process}

In this case the output are effective strain, stress, and temperature are considered. Hence in case of stress strain and Temperature smaller is better has taken for the analysis.

4.3.2 Effect of speed and feed rate on effective stress and effective strain

The effective-stress and strain at varied speeds 3000, 3500, and $4000 \mathrm{rpm}$, feed rates 30,40 , and $50 \mathrm{~mm} / \mathrm{min}$ are observed and analyzed as shown in Table 2. Results for effective stress, effective strain and temperature by changing the feed rates. With the help Taguchi analysis design of experiments were conducted and analyzed the obtained result. The following table3.shows the $\mathrm{S} / \mathrm{N}$ rations \& mean with respective effective stress, strain, and temperature.

Table. $2 \mathrm{~S} / \mathrm{N}$ ratio and means for effective stress and effective strain

\begin{tabular}{|c|c|c|c|c|c|c|c|}
\hline S.N0 & $\begin{array}{l}\text { Speed } \\
(\mathrm{rpm})\end{array}$ & $\begin{array}{c}\text { Feed } \\
(\mathrm{mm} / \mathrm{min})\end{array}$ & $\begin{array}{c}\text { Effective stress } \\
(\mathrm{MPa})\end{array}$ & $\begin{array}{c}\text { Effective } \\
\text { strain }\end{array}$ & $\begin{array}{l}\text { Temp } \\
\left({ }^{\circ} \mathrm{C}\right)\end{array}$ & SNRA1 & MEAN1 \\
\hline 1 & \multirow{3}{*}{3000} & 30 & 700 & 10.3 & 491 & -53.86 & 400.43 \\
\hline 2 & & 40 & 701 & 6.66 & 463 & -53.71 & 390.22 \\
\hline 3 & & 50 & 716 & 5.15 & 422 & -53.62 & 381.05 \\
\hline 4 & \multirow{3}{*}{3500} & 30 & 700 & 6.84 & 487 & -53.84 & 397.94 \\
\hline 5 & & 40 & 714 & 4.30 & 476 & -53.89 & 398.10 \\
\hline 6 & & 50 & 703 & 5.74 & 478 & -53.81 & 395.58 \\
\hline 7 & \multirow{3}{*}{4000} & 30 & 720 & 13.1 & 504 & -54.10 & 412.36 \\
\hline 8 & & 40 & 700 & 5.54 & 455 & -53.66 & 386.84 \\
\hline 9 & & 50 & 702 & 7.94 & 453 & -53.74 & 387.64 \\
\hline
\end{tabular}

From the response Table 2, Figures 7 and 8 it is observed that speed of $3500 \mathrm{rpm}$ and $30 \mathrm{~mm} / \mathrm{min}$ feed rate are effecting the process for the set of values obtained by the simulation analysis.

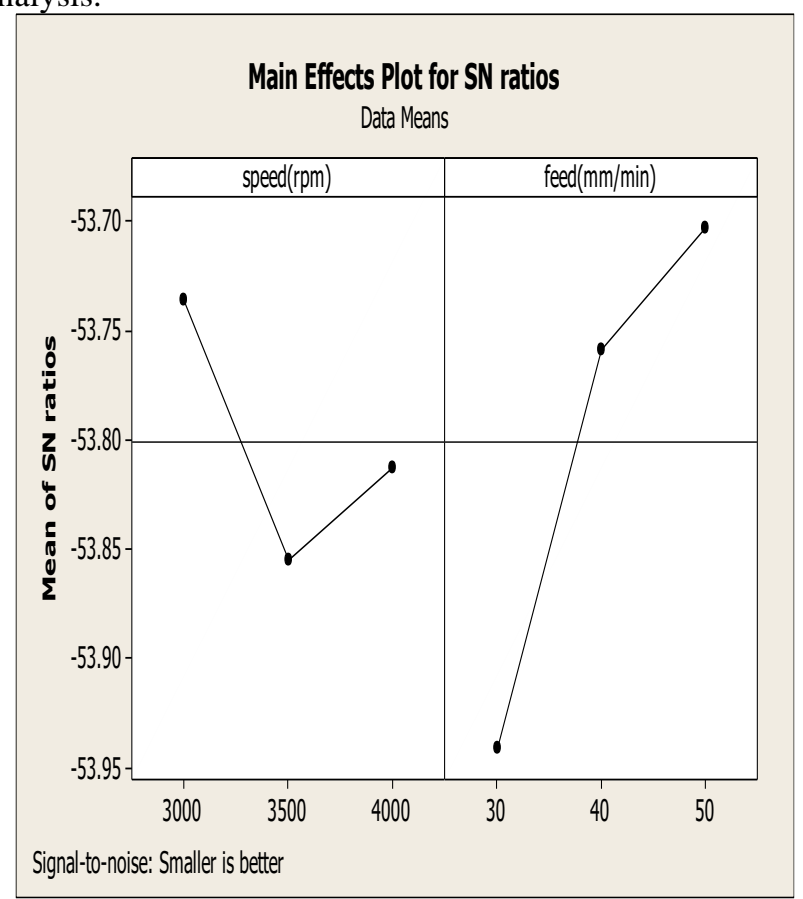

Figure 7 Graph for $\mathrm{S} / \mathrm{N}$ ratio

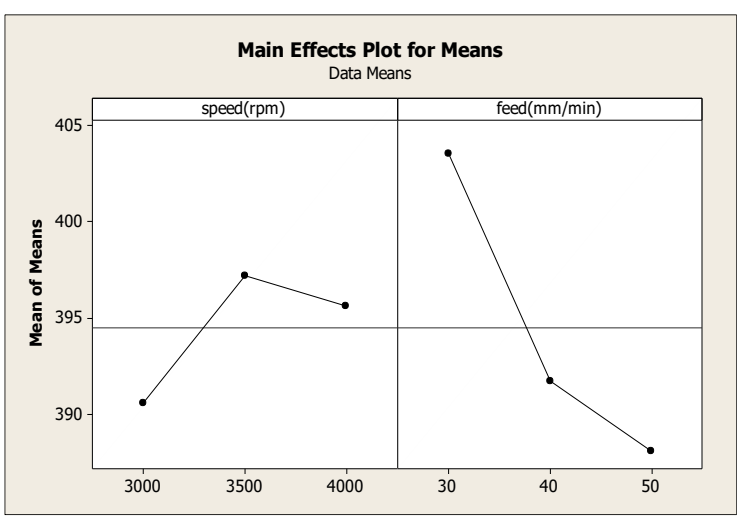

Figure 8 Graph for mean of means

\section{CONCLUSION}

Modeling and simulation of Friction drilling has been performed using DEFORM-3D software. Analysis of results has been performed by using MINITAB software. The Friction drilling of AL7075-T351 with Tungsten carbide tool has simulated and observed that there is no chip formation in Friction drilling and there is a slight variation in effective stress by varying speeds and feed rates. Table 3 and figure $7 \& 8$ shows that when spindle speed, and feed rate increases, Effective Stress in friction Drilling increases. Where the effective increases with increasing speed, improper bushing formation will occur with increase of speed.

\section{ACKNOWLEDGEMENT}

The authors would like to acknowledge the support given by Department of Science and Technology, Ministry of Science and Technology, India funded project work titled 'Development and implementation of online adaptive controller design for CNC milling' through fund sanction order D.O: SB/FTP/ETA-262/2013, DST, New Delhi, India.

\section{REFERENCES}

1. Eliseev, A.A., Fortuna, S.V., Kolubaev, E.A. and Kalashnikova, T.A., 2017. Microstructure modification of 2024 aluminum alloy produced by friction drilling. Materials Science and Engineering: A, 691, pp.121-125.

2. Chow, H.M., Lee, S.M. and Yang, L.D., 2008. Machining characteristic study of friction drilling on AISI 304 stainless steel. Journal of materials processing technology, 207(1-3), pp.180-186.

3. Demir, Z., Özek, C. and Bal, M., 2018. An Experimental Investigation on Bushing Geometrical Properties and Density in Thermal Frictional Drilling. Applied Sciences, 8(12), p.2658.

4. Ozler, L. and Dogru, N., 2013. An experimental investigation of hole geometry in friction drilling. Materials and Manufacturing Processes, 28(4), pp.470-475.

5. Demir, Z., 2016. An Experimental Investigation of the Effect of Depth and Diameter of Pre-drilling on Friction Drilling of A7075-T651. Journal of Sustainable Construction Materials and Technologies, 1(2), pp.46-56.

6. Raju, B.P. and Swamy, M.K., 2012. Finite element simulation of a friction drilling process using deform-3D. International Journal of Engineering Research and Applications, 2(6), pp.716-721.

7. Miller, S.F., Tao, J. and Shih, A.J., 2006. Friction drilling of cast metals. International Journal of Machine Tools and Manufacture, 46(12-13), pp.1526-1535.

8. Miller, S.F., Li, R., Wang, H. and Shih, A.J., 2006. Experimental and numerical analysis of the friction drilling process. Journal of Manufacturing Science and Engineering, 128(3), pp.802-810. 
9. El-Bahloul, S.A., El-Shourbagy, H.E., Al-Makky, M.Y. and El-Midany, T.T., 2013. Thermal friction drilling: (a review). In 15th International Conference on Aerospace Sciences \& Aviation Technology, Cairo, Egypt.

10. Prasad, B.S. and Babu, M.P., 2017. Correlation between vibration amplitude and tool wear in turning: Numerical and experimental analysis. Engineering Science and Technology, an International Journal, 20(1), pp.197-211.

11. Reddy, Y.R.M. and Prasad, B.S., Simulation of form tolerances using $\mathrm{cmm}$ data for drilled holes-an experimental approach. Journal of Production Engineering, 19(2), pp. 77-83.

12. Reddy, Y.R.M. and Prasad, B.S., 2017. Analysis of vibration assisted drilling-A base for tool performance evaluation. J. Prod. Eng, 20(1), pp. 1-15.

13. Prasad, B.S. and Kiran, D.S.R., 2019. Experimental investigation to optimize tool performance in high-speed drilling: a comparative study. Journal of the Brazilian Society of Mechanical Sciences and Engineering, 41(11), p.535.

\section{AUTHORS PROFILE}

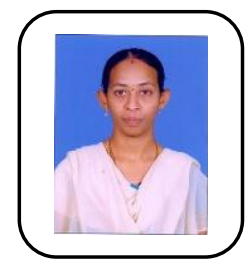

Ms. Nimmagadda Srilatha, M.Tech (CAD/CAM) working as Assistant Professor in Mechanical Engineering, VNRVJIET, Hyderabad since 2014. Ms. Srilatha pursuing her Ph.D. under the supervision of Dr.Balla Srinivasa Prasad, Associate Professor at GITAM Deemed to be University, Visakhapatnam, India-530045.

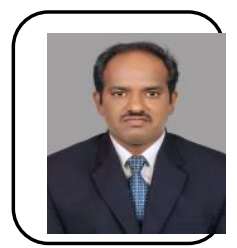

Dr. Balla Srinivasa Prasad presently working as Associate Professor in Mechanical Engineering, GIT, GITAM, Visakhapatnam since 2003. He was graduated in B.E (Mechanical Engg) from Andhra University- Visakhapatnam, Master's degree in Production Engineering from S V University, Tirupati. He was awarded Ph.D. from Andhra University in 2010. Dr Balla so far published 30 peer reviewed publications and actively engaged in research in fields of Additive manufacturing, Tool condition monitoring and multi sensor fusion etc.

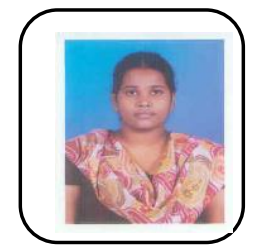

Ms. Padmaja Anipey graduated in B.E. (MPIE) from GITAM College of Engg (AU), Visakhapatnam. She obtained Master's degree in HTES from Andhra University, Visakhapatnam. She has more than 6 years of experience for teaching B.Tech students. 